\title{
EVALUATION OF THE POLICE OPERATIONAL TACTICAL PROCEDURES FOR REDUCING OFFICER INJURIES RESULTING FROM PHYSICAL INTERVENTIONS IN PROBLEMATIC ARRESTS. THE CASE OF THE MUNICIPAL POLICE OF CÁDIZ (SPAIN)
}

\section{JOSE CARLOS VERA JIMÉNEZ ${ }^{1}$, FRANCISCO FERNANDEZ², JESUS AYUSO, and JOSE ANTONIO LORENTE ACOSTA ${ }^{4}$}

${ }^{1}$ City Hall of Cádiz, Cádiz, Spain

${ }^{2}$ University of Cádiz, Cádiz, Spain

Department of Industrial Engineering and Civil Engineering

${ }^{3}$ University of Cádiz, Cádiz, Spain

Physical Chemistry Department

${ }^{4}$ Pfizer-University of Granada-Junta de Andalucía Centre for Genomics and Oncological Research (GENYO), Granada, Spain

\begin{abstract}
Objectives: This paper describes some operational tactical procedures (OTP) and discusses the results of a 14-year-long study, spanning the period 2003-2016, conducted by the Municipal Police of Cádiz, Spain, which comprised 3 time periods: 2003-2006, when the officers were trained in traditional policing procedures; 2007-2013, when the officers were taught an innovative set of OTP in the form of a basic set of self-defense and arrest mechanisms, different from the traditional policing procedures that rely on martial arts and combat sports; and finally 2014-2016, when the OTP training was discontinued. The aim of this study was to improve policing and reduce officer injuries resulting from interventions in controversial or violent situations, such as problematic arrests. Material and Methods: The study involved 162 police officers and commanders of the Municipal Police of Cádiz, who were in street duty for their first time. There were 8 females and 154 males aged 24-55 years. Three OTP stages are shown as examples. Results: Based on the analysis of "training hours" and "physical interventions in problematic arrests," the results were: 1) the number of sick leaves in the police was identical according to the number of arrests, and 2) data on sick leaves show remarkable differences among the 3 periods under analysis. Conclusions: The OTP-based training substantially reduced officer sick leaves. The overall reduction in sick leaves in the period 2007-2013 was observed that cannot be ascribed to a decrease in criminal acts, and hence in police physical interventions. Int J Occup Med Environ Health. 2020;33(1):35-43
\end{abstract}

Key words:

use of police force, operational tactical procedures, arrest and self-defense skills, injury leaves prevention, prevention of labor risks, criminology

Funding: this study was supported by the University of Cádiz (grant No. PR2017-007 entitled "Plan Propio," grant manager: Prof. Jesus Ayuso). This study was supported by the UCA 2017 program for the promotion of research and their transfer.

Received: January 9, 2019. Accepted: September 6, 2019.

Corresponding author: Jose Carlos Vera Jimenez, City Hall of Cádiz, Plaza San Juan de Puerto Rico, s/n, 11010 Cádiz, Spain (e-mail: josecarlos.verajimenez@cadiz.es). 


\section{INTRODUCTION}

Comprehensive Occupational Health and Safety (OHS) programs comprise 3 essential elements, namely [1]:

- knowledge (to identify and evaluate threats),

- control and prevention (through training, exercise and education),

- maintenance and improvement (through research, the analysis of results, the revision of procedures and policies, and communication).

This paper discusses the results of the first 2 stages of a non-comprehensive OHS program implemented by the Municipal Police of Cádiz (southern Spain) in 2005-2013 to facilitate the acquisition of effective arrest and selfdefense skills (ASDS), with a view to reducing sick leaves among police officers, and a comparison of 3 years without any training. The program was based on a study of police officers that suggested the need for specific training in physical interventions during problematic arrests to replace previous procedures based on regular ASDS [2]. The new so-called "operational tactical procedures" (OTP) are a set of primary responses in the form of tactical movements, according to Vera-Jiménez [3].

Most of the police training in physical interventions during problematic arrests has so far relied on martial arts and combat sports. Some studies endorse the use of martial arts for improved police performance as regards anxiety control [4]. However, the actual use of these arts or combat sport techniques in police interventions has been questioned because it can result in severe damage to both officers and their opponents. The true value of experience in martial arts has also been questioned, especially in situations of high anxiety [4].

Aggressive approaches to police intervention were deemed highly useful more than half a century ago. For example, like other countries had done before, the U.S. Defensive Tactics Manual [5] recommended attacking vital body parts or organs (liver, spleen, solar plexus, head) to reduce opponents. This traditional tactical approach con- tinues to be favored in many countries, particularly in eastern regions [6], but drastic interventions leading to opponents being defeated in an extreme form are discouraged. Like the military training which caused so many problems in the past [7], these police training procedures can be deemed obsolete in the 21st century.

In response to the increasing criticism of former tactics, the police adopted non-lethal weapons such as taser, tear gas, pepper spray or batons. These devices also met with some criticism [8,9] and, fortunately, were not thoroughly adopted.

Police training based on reflex-based self-defense mechanisms for acting in high-pressure arrest situations has been recently found to improve ASDS [10]. The operational procedures examined in this work may be similarly efficient for this purpose [3].

Police OTP are intended to avoid physical damage even in those situations where problematic arrests generate no anxiety. These procedures rely on the internalization of a series of body movements allowing officers to deliver specific tactical reflex responses in physical interventions during problematic arrests. These reflex skills are designed to avoid the overloading of the officer's body as a result of using force, being replaced with a change in weights. Blows, pressures and manipulations target non-vital areas of the opponent's body to facilitate reduction and beating, but without causing serious or even fatal injuries. Also, being a man or woman, tall or short, strong or weak, is not decisive for achieving the primary goal. However, these tactical procedures are the result of the sustained updating of former procedures since 1997, when training in defense techniques based on martial arts prevailed. Progress in OTP has run in parallel with research into the topic by such authors as Nieuwenhuys et al. [2] and Renden et al. [4,10], who have concluded that improving police performance in problematic arrests requires training officers in specific tactics.

Police training in physical intervention techniques is usually too short for the taught procedures to be properly 
internalized, and hence their effectiveness is dubious. For example, the basic course for admission to the Andalusian Public Safety School allocates only 30/1800 h to this type of training and yet officers are expected to act efficiently, but also sensibly and moderately, in all violent situations [10].

Police OTP have so far been regulated by the Spanish national OHS law. Soon, however, they will be placed under the umbrella of the Municipal Police OHS law to be passed by the Andalusian Regional Parliament [11].

Operational tactical procedures are based on 3 pillars:

1) what is established in the international and Spanish legislation on the use of force;

2) the limits established by legal medicine on the possible injuries that may be caused during a physical intervention, following the principles of proportional use of force;

3 ) the reduction of injuries in the police officers in said actions.

With respect the first one, the authors highlight:

- The Code of Conduct for Law Enforcement Officials of the United Nations (resolution No. 34/169 of December 17, 1979) [12], with Article 3 reading as follows: "Law enforcement officials may use force only when strictly necessary and to the extent required for the performance of their duty."

- Resolution 690 (1979) of the Parliamentary Assembly of the Council of Europe, Declaration on the Police [13] and Recommendation Rec(2001)10 of the Committee of Ministers to Member States on the European Code of Police Ethics [14].

Regarding the second pillar, legal medicine provides enough knowledge about the kind of injures which can affect citizens, depending on the area of the human body which is hit or pressed, taking into account a series of criteria (Figure 1) [3].

Regarding the third pillar, police officers are usually trained in martial arts in well-equipped, large gyms. By contrast, when acting in problematic arrests, they do

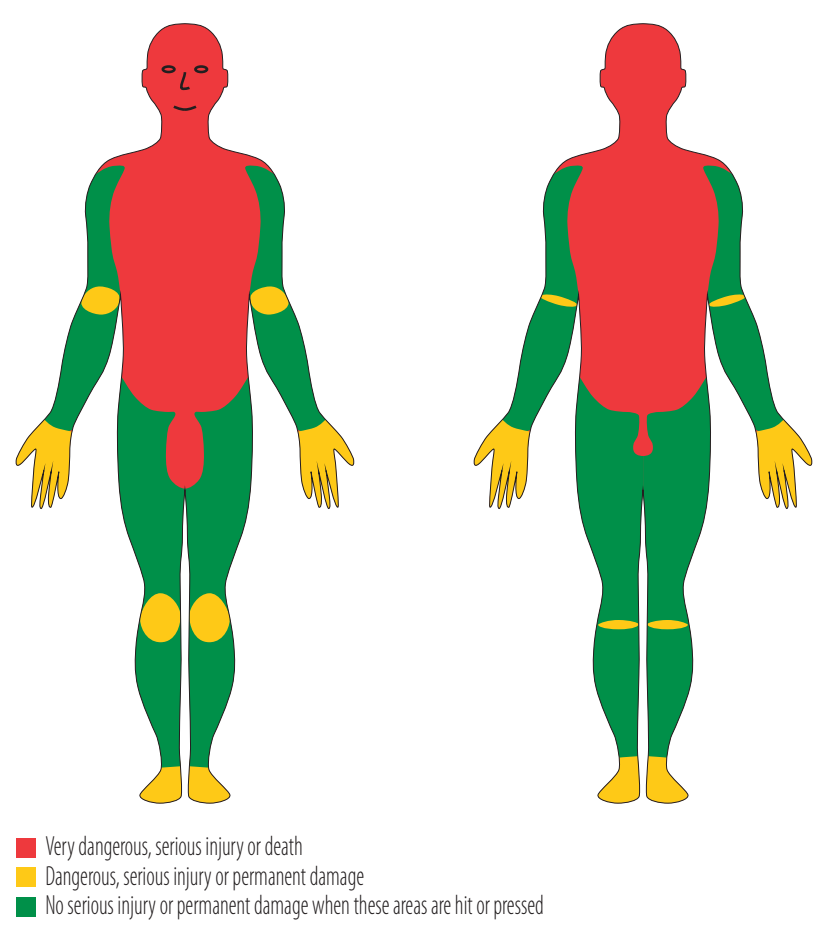

Figure 1. Three areas of the human body where different levels of damage can be generated

not wear loose and comfortable apparel, and they often have to land on hard ground or asphalt, rather than on soft tatami. In addition, they have no chance to warm up before acting, which frequently leads to injuries. The types of injuries resulting from police interventions have been the subject of some research $[15,16]$, especially prominent of which is a statistical review [17,18] which is consistent with the medical diagnosis of the injuries observed in the Municipal Police of Cádiz. As in many other situations, however, prevention is better than cure in order to avoid officer injuries and the ensuing sick leaves. Faced with the fatal consequences of the decreasing number of active police officers, attempting to reduce injuries is the reason for the present work.

This paper examines the results of a 14-year-long followup study of the number of injury leaves among officers of the Municipal Police of Cádiz, resulting from physical interventions in problematic arrests, over 3 periods where 
the officers received no specific training, OTP training and no training. No personal information about the participating officers was collected. Also, the Spanish law on data protection was abided by, and the applicable ethical principles regarding the use and dissemination of sensitive information were adhered to at all times [19].

In the period in which the OTP training program was carried out, other expert training courses (instructions in specific techniques of the prevention of occupational risks in the police and the military) were also taught by the University of Cádiz in Spain, Mexico, Costa Rica, Dominican Republic, Colombia, Argentina and Portugal. All of them were based on the same procedures of OTP training.

\section{MATERIAL AND METHODS}

\section{Statistics}

Some statistical tests were necessary to prove the results obtained in a contrasted way. Prior to the analysis, the numerical variable "training hours" was converted into the following 3 categorical variables according to the training stage:

- "no specific training,"

- "OTP training,"

- "no training."

Likewise, the variable "physical interventions in problematic arrests" was converted into 2 categorical variables according to the number of arrests, namely:

- "greater than average,"

- "smaller than average."

The ideal data treatment would have been 2-way analysis of variance (ANOVA) with the number of "sick leaves" as the dependent variable, and those of "training hours" and "physical interventions in problematic arrests" as factors or independent variables. However, sick leaves exhibited a non-normal distribution for these factors ( $p$-values for the Shapiro-Wilk tests were $<0.05$ ), and non-parametric Kruskal-Wallis tests had to be applied instead. These tests were done with the SPSS software [20].
Finally, an analysis based on the Mann-Whitney U test (since variances were unequal) was carried out.

\section{Description of OTP}

Theoretical and practical studies about the needs of police interventions over citizens in a democratic society under the rule of law, according to the guidelines of international rules in order to protect citizens, have been developed from the point of view [12-14] of the prevention of occupational risks, and the prevention of risks in general, offering protocols, techniques and procedures of the police interventions specifically focused on the work of these forces and security units, which are referred to as operational tactical procedures. These procedures were created to supply the agents with:

- safety during the intervention,

- confidence and faith in the colleagues,

- minimizing stress,

- improving the social image of the police force,

- improving social services,

- high police quality,

- avoiding injuries during police interventions,

- decreasing sick leaves,

- decreasing injuries of citizens.

The objectives that the OTP training program is intended to achieve are:

- creating an operative intervention system applied to the needs of policemen;

- respecting the fundamental rights of citizens, taking detailed care of critical points in the case of detention while respecting legal medicine;

- developing risk prevention of policemen, deepening safety measures;

- reducing sick leaves which, according to the criminological research, are related to the hours of training;

- decreasing the complaints against the police due to the inappropriate use of physical strength, applying changes of techniques that the police were using 


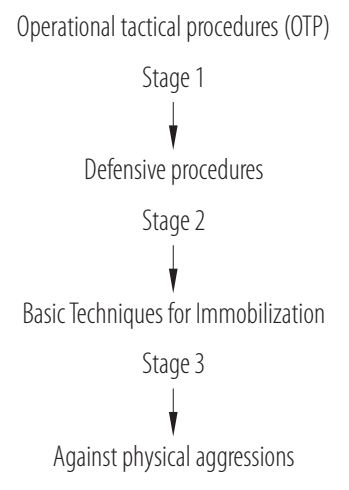

Figure 2. The first 3 stages of the operational tactical procedures (OTP) examined in the study on OTP that involved 162 police officers and commanders of the Municipal Police of Cádiz, Spain

during physical interventions prior to the imparted training.

The OTP training described in Figure 2 was conducted in a sequence of 3 stages.

\section{RESULTS}

The study involved 162 police officers and commanders of the Municipal Police of Cádiz, who were in street duty for their first time. There were 8 females and 154 males aged 24-55 years. Data were obtained from the Occupational Health Office of the City Council, attestation reports of the Municipal Police and the Public Safety School of Cádiz.

The occupational health data used were as follows:

- Number of training hours. A distinction was made between a pre-OTP stage (2003-2006) and an OTP training stage (2007-2013) (Figure 3). On average, each module was attended by around 45 officers. By way of example, Figure 4 shows the number of officers in each module in the 2013 course, which was similar to those for the previous years. There was no training after that.

- Number of sick leaves resulting from injury in physical interventions, recorded for the period 2005-2016 (Figure 5).

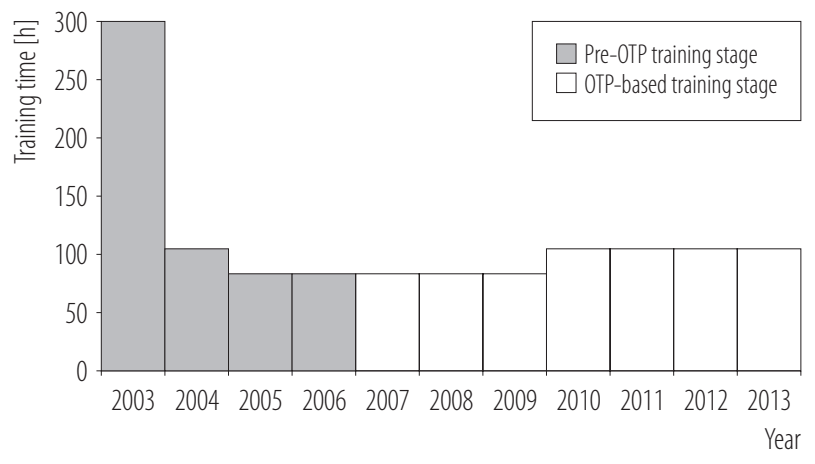

OTP - operational tactical procedures.

Figure 3. Time in the pre-operational tactical procedures (OTP) training stage and the OTP training stage each year, in the study on OTP that involved 162 police officers and commanders of the Municipal Police of Cádiz, Spain

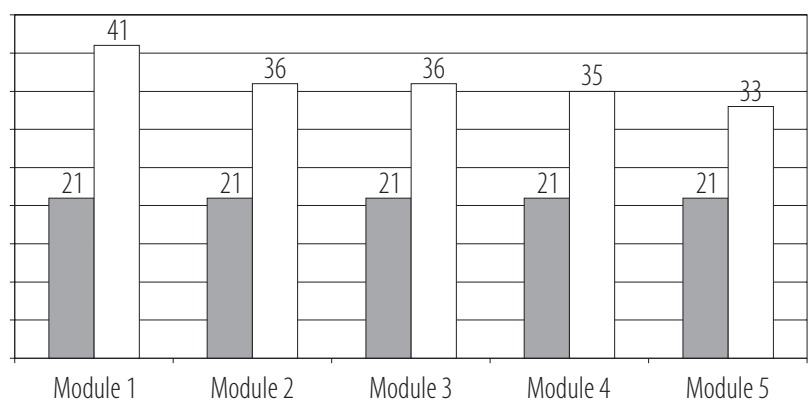

Training time [h]

$\square$ Police officers trained [n]

Figure 4. Distribution of training hours among modules in the last year of operational tactical procedures (OTP) training (2013), and the number of officers trained, in the study on OTP that involved 162 police officers and commanders of the Municipal Police of Cádiz, Spain

- Number of arrests for disobeying, offending, resisting or attacking the police in Cádiz over the period 20052016 (Figure 5). These data oscillate smoothly in the period and the values range approx. $267 \pm 25$.

A breakdown of the types of police interventions and the types of injuries in the police are summarized in Table 1, together with baseline data of the police officers. 


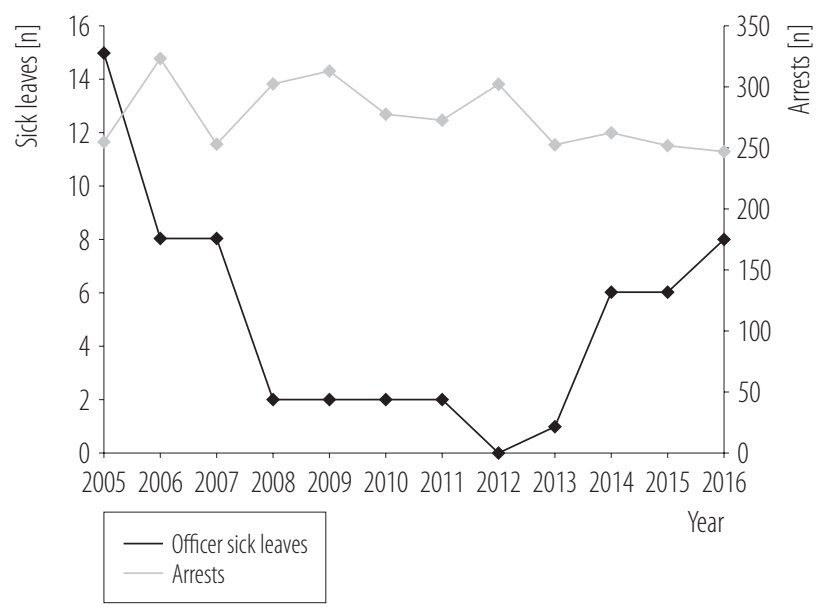

Figure 5. Officer sick leaves by injury resulting from physical interventions during problematic arrests in the training stage (2005-2006), the operational tactical procedures (OTP) training stage (2007-2013) and the no-training stage (2014-2016), and arrests performed by the Municipal Police of Cádiz during problematic physical interventions in 2005-2016, in the study on OTP, that involved 162 police officers and commanders of the Municipal Police of Cádiz, Spain

The results suggest the importance of OTP for the reduction of injuries in the police officers of Cádiz when they had interventions in problematic arrests. However, such conclusions could be more clearly evidenced by a study based on statistical inference.

After applying the Kruskal-Wallis tests, the results suggest the importance of OTP for the reduction of injuries in the police officers of Cádiz when they had interventions in problematic arrests:

- the number of sick leaves between the 2 categories of physical interventions in problematic arrests was identical,

- data on sick leaves show remarkable differences among the 3 categories of training hours.

The Shapiro-Wilk and Kruskal-Wallis tests were done with the SPSS software [20]. Table 2 summarizes the statistical results for the non-parametric test.

\section{DISCUSSION}

The common injuries resulting from physical interventions in problematic arrests were those of the hands and fin-
Table 1. Characteristics of the variables in the study on operational tactical procedures (OTP) that involved 162 police officers and commanders of the Municipal Police of Cádiz, Spain

\begin{tabular}{|c|c|}
\hline Variable & $\begin{array}{c}\text { Participants } \\
(\mathrm{N}=162)\end{array}$ \\
\hline \multicolumn{2}{|l|}{ Baseline police officers } \\
\hline male $[\%]$ & 95 \\
\hline age [years] (range) & $24-55$ \\
\hline race (white) [\%] & 100 \\
\hline employed [\%] & 100 \\
\hline educational level ( $\geq$ graduated) [\%] & 35 \\
\hline previous injury treatment [\%] & 0 \\
\hline \multicolumn{2}{|l|}{ Type of police intervention [\%] } \\
\hline faults & 33 \\
\hline disobedience & 19 \\
\hline disparagement & 2 \\
\hline insults & 8 \\
\hline threats & 5 \\
\hline resistance & 20 \\
\hline attacks & 12 \\
\hline \multicolumn{2}{|l|}{ Type of injuries in the police [\%] } \\
\hline fingers-hand & 38 \\
\hline back & 21 \\
\hline arm-forearm & 17 \\
\hline thorax-chest & 8 \\
\hline cervical-neck & 8 \\
\hline hip-leg & 8 \\
\hline
\end{tabular}

gers - a likely result of gripping during struggle - and also those of muscles due to blows, falls, etc. The latter were more common in the first 3 years, and probably resulted from officers not having as much space as when applying conventional reduction procedures based on martial arts in places where police interventions occurred. Also, police uniforms proved less suitable than the training apparel to apply such procedures, and the ground and objects on the streets were much harder than tatami in the gym. Traumatic injuries (cervical vertebrae, hip, and thorax) were less common. Consistent with previous results 
Table 2. Results of the Kruskal-Wallis tests in the study on operational tactical procedures (OTP) that involved 162 police officers and commanders of the Municipal Police of Cádiz, Spain

\begin{tabular}{lccc}
\hline \multicolumn{1}{c}{ Null hypothesis } & $\mathrm{p}$ & Decision \\
\hline $\begin{array}{l}\text { The distribution of sick leaves among the } 2 \text { categories of physical interventions } \\
\text { in problematic arrests was identical. }\end{array}$ & 0.182 & null hypothesis was not rejected \\
$\begin{array}{l}\text { The distribution of sick leaves among the } 3 \text { categories of training hours } \\
\text { was identical. }\end{array}$ & 0.009 & null hypothesis was rejected \\
\hline
\end{tabular}

For the last result, a post-hoc analysis based on the Mann-Whitney U test revealed that the "OTP training" group differed markedly from the other 2 groups as regards sick leaves.

The significance is $\alpha \leq 0.05$.

of $[17,18]$, the most serious injuries arose from attacks on officers or from the need to use force without time to warm up their muscles. Changes and adaptations of the procedures taught to reduce the number of sick leaves were developed in function of the injury type (especially in the first 3 years). Thus, replacing traditional procedures for reducing opponents with others, requiring no warmup, led to a decrease in sick leaves due to muscle injuries. This was also the case with blocking opponents by the forearm when grabbing.

Although Cádiz currently has a population slightly exceeding 120 000, it is not a conflict city. Also, its crime rate is low by Spanish standards [21]. The number of arrests in the city exhibited no significant increase or decrease during the period of this study (2003-2016). Therefore, the observed reduction in sick leaves among officers in that period cannot be ascribed to a decrease in physical interventions in response to one in criminal acts.

The results of this study should be understood as referring to a local area within Spain but, as indicated above, with a crime rate within the Spanish and European average.

It should be noted that a limitation of the current study is that only the main injuries of police officers were considered. This means that the number of injuries recorded may underestimate the total number. However, the authors think that the main injuries are the most influential in sick leaves. Additionally, in some cases, officers were able to complete their own injury reports (as in minor injuries), which may provide some degree of subjectivity in the injury report (attaching a greater or lesser importance).

Despite these limitations, the current findings reflect an important step in reducing injuries suffered by police officers when they are on duty if OTP techniques are applied.

\section{CONCLUSIONS}

The conclusions reached according to the objectives are as follows.

1. A specific training program was implemented in 2003 2013 to reduce the number of injury leaves resulting from physical interventions in problematic arrests by the municipal police officers in the city of Cádiz. An innovative set of operational tactical procedures was introduced in the last stage of this period (2007-2013).

2. The overall reduction in sick leaves in 2007-2013 was observed that cannot be ascribed to a decrease in criminal acts, and hence to a decrease in police physical interventions.

Despite these results, more extensive studies are required to confirm the usefulness of specific police training based on innovative procedures like OTP for such purposes as reducing injuries among citizens.

\section{REFERENCES}

1. Sanberg EL, Brito CS, Luna AM, McFadden SM. A guide to occupational health and safety for law enforcement executives [Internet]. Washington DC: Bureau of Justice 
Assistance, U.S. Department of Justice, Police Executive Research Forum; 2010 [cited 2019 Aug 7]. Available from: https:/www.bja.gov/Publications/PERF_LE_OccHealth.pdf.

2. Nieuwenhuys A, Caljouw SR, Leijsen MR, Schmeits BAJ, Oudejans RRD. Quantifying police officers' arrest and self-defence skills; Does performance decrease under pressure? Ergonomics. 2009;52(12):1460-8. https://doi.org/10. 1080/00140130903287981.

3. Vera-Jiménez JC. [Police intervention and risk prevention OTP: Prevention of occupational risks and protection of citizens]. Saarbrücken: Publicia; 2016. Spanish.

4. Renden PG, Landman A, Savelsbergh GJP, Oudejans RRD. Police arrest and self-defence skills; performance under anxiety of officers with and without additional experience in martial arts. Ergonomics. 2015;58(9):1496-506. https://doi. org/10.1080/00140139.2015.1013578.

5. Hoover EJ. Defensive tactics. A handbook for law enforcement officers. Washington DC: F.B.I; 1951.

6. Renden PG, Nieuwenhuys A, Savelsbergh JPG, Oudejans RRD. Dutch police officers' preparation and performance of their arrest and self-defence skills: A questionnaire study. Appl. Ergon. 2015;49:8-17.

7. Kraska PB. Militarizing American Police: The rise and normalization of paramilitary units. Soc Probl. 1997;44(1):1-18.

8. Mesloh C, Henych M, Hougland S, Thompson F. Taser and less lethal weapons; an exploratory analysis of deployments and effectiveness. Law Enfor Exec Forum, 2005;5(5): 67-79.

9. Mesloh C. Less lethal weapon effectiveness, use of force, and suspect and officer injuries: a five-year analysis. A report to the National Institute of Justice [Internet]. Fort Myers: Florida Gulf Coast University; 2008 [cited 2019 Aug 7]. Available from: https://www.ncjrs.gov/pdffiles1/nij/ grants/224081.pdf.

10. Renden PG, Savelsbergh JP, Oudejans RRD. Effects of reflexbased self-defence training on police performance in simulated high-pressure arrest situations. Ergonomics. 2017;60(5): 669-79, https://doi.org/10.1080/00140139.2016.1205222.
11. Junta de Andalucía [Internet]. Sevilla: The Organization; c2007 [cited 2019 Aug 7]. [The justice department of the Andalusian regional government]. Available from: http://www. juntadeandalucia.es/organismos/justiciaeinterior/areas/policia/espa/paginas/plan-formacion-espa.html. Spanish.

12. Code of Conduct for Law Enforcement Officials of the United Nations [Internet]. Geneva: Office of the United Nations High Commissioner for Human Rights (OHCHR) [cited 2019 Aug 7]. Available from: https://www.ohchr.org/EN/ ProfessionalInterest/Pages/LawEnforcementOfficials.aspx

13. Resolution 690 of 1979, of the Parliamentary Assembly of the Council of Europe, Declaration on the Police. [Internet]. Strasbourg: The Assembly; 1979 [cited 2019 Aug 7]. Available from: http://www.assembly.coe.int/nw/xml/XRef/XrefDocDetails-en.asp?FileID=16101\&lang=en .

14. Recommendation Rec.(2001)10 of the Committee of Ministers of the Member States on the European Code of Ethics of the Police [Internet]. Strasbourg: The Committee; 2001. [cited 2019 Aug 7]. Available from: https://www.refworld. org/docid/43f5c7944.html.

15. Summerfield D. Metropolitan Police blues: protracted sickness absence, ill health retirement, and the occupational psychiatrist. BMJ. 2011;342:d2127, https://doi.org/10.1136/ bmj.d2127.

16. Varvarigou V. Law enforcement duties and sudden cardiac death among police officers in United States; case distribution study. BMJ. 2014;349:g6534, https://doi.org/10.1136/bmj. g6534.

17. Lyons K. A profile of injuries sustained by law enforcement officers; A critical review. Int J Environ Res Public Health. 2017;14(2):142, https://doi.org/10.3390/ijerph14020142.

18. Larsen B, Aisbett B, Silk A. The Injury Profile of an Australian Specialist Policing Unit. Int J Environ Res Public Health. 2016;13(4):370, https://doi.org/10.3390/ijerph13040370.

19. Elkington J, Stevenson M, Haworth N, Sharwood L. Using police crash databases for injury prevention research A comparison of opt-out and opt-in approaches to study 
recruitment. Aust N Z J Public Health. 2014;38(3):286-9, https://doi.org/10.1111/1753-6405.12237.

20. SPSS $®$ Science software products, $233 \mathrm{~S}$. Wacker Drive, 11th floor, Chicago, IL 60606-6307 (SPSS Inc.: Chicago, IL, USA).
21. [Statistics Criminality in Spain 2016] [Internet]. Madrid: Ministry of the Interior; 2016 [cited 2019 Aug 7]. Available from: http://www.dsn.gob.es/es/actualidad/sala-prensa/estad\%C3\% ADsticas-criminalidad-espa\%C3\%B1a-2016. Spanish.

This work is available in Open Access model and licensed under a Creative Commons Attribution-NonCommercial 3.0 Poland License - http://creativecommons.org/ licenses/by-nc/3.0/pl/deed.en. 